\title{
Pronomes pessoais na interlíngua do surdo aprendiz de português (L2) escrito
}

DOI: http://dx.doi.org/10.21165/el.v49i3.2620

\section{Telma Rosa de Andrade' Heloisa Maria Moreira Lima-Salles²}

\section{Resumo}

O estudo investiga a interlíngua de surdos falantes da Língua de Sinais Brasileira (LSB) aprendizes de português brasileiro (PB) escrito como segunda língua (L2). Adotando a hipótese da interferência da L1, examinamos o uso do sistema pronominal na posição sintática de sujeito, no desenvolvimento da língua alvo (PB). Para tanto, tomamos como referência o papel do traço de animacidade na distinção entre verbos simples, que codificam o padrão "o corpo como sujeito", e verbos de concordância, que codificam o padrão "corpo-espaço" na LSB. Os resultados preliminares do teste experimental apontam para a existência de desenvolvimento linguístico em função do nível de escolarização, bem como para o papel do traço de animacidade como um efeito positivo de interferência da L1 no uso convergente do pronome de $3^{a}$ pessoa na interlíngua.

Palavras-chave: interlíngua; sistema pronominal; Língua de Sinais Brasileira; português brasileiro. 1 Universidade Federal de São João del Rei (UFSJ), São João Del Rei, Minas Gerais, Brasil;
rosatelmalibra@gmail.com; https://orcid.org/0000-0003-3912-0651

2 Universidade de Brasília (UnB), Brasília, Distrito Federal, Brasil; hsalles@unb.br; https://orcid.org/0000-0002-4190-1804 


\title{
Personal pronouns in the interlanguage of deaf learners of written Portuguese (L2)
}

\begin{abstract}
The study investigates the interlanguage of deafs that are users of the Brazilian Sign Language (BSL) learning (written) Brazilian Portuguese (BP) as a second language (L2). Adopting the first language (L1) interference hypothesis, we examine the use of the pronominal system in subject position in the development of $L 2$. In the analysis, we take into consideration the role of animacy in the distinction between simple verbs, which encode the pattern "body as subject", and agreeing verbs, which encode the pattern "bodyspace" in BSL. The preliminary results of the experimental test point to the existence of language development as a function of schooling, as well as to the role the feature [+animate] as a positive effect of L1 interference in the adequate use of the third person pronoun in the interlanguage.
\end{abstract}

Keywords: interlanguage; pronominal system; Brazilian Sign Language; Brazilian Portuguese.

\section{Introdução}

O estudo investiga o uso do sistema pronominal na interlíngua de surdos aprendizes de português escrito como segunda língua (L2) e que têm a língua de sinais brasileira (LSB) como a primeira língua (L1). Para tanto, adotamos a hipótese de que a linguagem humana é uma capacidade inata - a Faculdade de Linguagem -, definida formalmente em termos da teoria da Gramática Universal (conforme Chomsky, 1994, 1999). Em relação à aquisição da L2, adotamos a hipótese do acesso parcial à GU no desenvolvimento da interlíngua (conforme White, 2003). Nesse sentido, investigamos a interferência da L1, considerada o estado mental inicial no desenvolvimento da língua alvo (L2), bem como o acesso aos princípios invariantes da $\mathrm{GU}^{3}$.

Para tanto, partimos do contraste, a seguir, entre o português e a LSB. Em português, o sujeito pronominal na posição de sujeito é marcado pelo pronome 'ele' e pela flexão verbal na $3^{\mathrm{a}}$ pessoa do singular, e na posição do objeto, o pronome 'você', de $2^{\mathrm{a}}$ pessoa, é

3 Este artigo reporta aspectos gerais do estudo de Andrade (2016), incluindo, além de uma nova abordagem para a sistematização dos resultados quantitativos, novos subsídios teóricos para a discussão dos fenômenos gramaticais observados. 
pós-verbal, conforme ilustrado em (1)4. Da mesma forma, em LSB, a apontação é usada na direção do referente para preencher as mesmas posições, conforme ilustrado em (2) ${ }^{5}$.

\author{
Ele ama você. \\ IX ${ }_{3}$ s AMAR IX2s. 'Ele ama você.'
}

Tendo em vista as propriedades do português e da LSB na codificação das pessoas do discurso, o presente estudo investiga o desenvolvimento do sistema pronominal pelos surdos aprendizes de português (escrito) como L2. Tal processo manifesta-se, por hipótese, na interlíngua, definida originalmente pelo linguista Larry Selinker, citado por Elis (1997, p. 33, tradução e adaptação nossas), como um sistema linguístico único e autônomo, "que se constitui parcialmente com base na L1, mas que dela se distingue assim como da língua alvo"6. Assumindo-se a hipótese do acesso (parcial) à GU, a gramática da interlíngua é um sistema mental que se manifesta por fases, em função do acesso ao input da língua alvo e dos efeitos de interferência da L1. A complexidade desse processo pode ser discutida em diferentes perspectivas. Neste estudo, interessa investigar a reestruturação do sistema gramatical, em relação ao uso das categorias pronominais, tendo em vista a hipótese do acesso (parcial) à GU (conforme mencionado anteriormente).

Nesse sentido, a análise da interlíngua do surdo aprendiz de português (L2) escrito permite verificar a natureza do desenvolvimento linguístico. Considerando-se o contraste entre os dados em (1) e (2), a hipótese é a de que a interferência seja positiva, uma vez que os pronomes ocorrem como morfemas independentes, e a ordem dos termos na estrutura oracional é SVO nas duas línguas - essas propriedades serão retomadas adiante. No entanto, existem diferenças nas propriedades dos sistemas pronominais em cada língua, destacando-se o efeito da modalidade, uma vez que as LS são visuais-espaciais e as

4 Não consideramos, em (1), o fato de que, em português, os pronomes na posição de objeto podem ser clíticos/átonos ("me", "te", "nos") e, nesses casos, sua colocação é determinada por propriedades independentes (podendo ser pré-verbal ou pós-verbal). Voltaremos a essa questão.

5 Os dados de LSB são transcritos em caixa alta, com palavras do português, conforme Felipe (1998). A apontação é transcrita por IX (conforme QUADROS; KARNOPP, 2004), com as pessoas do discurso indicadas em fonte subscrita, conforme a seguir: $1 \mathrm{~s} / \mathrm{p}, 2 \mathrm{~s} / \mathrm{p}, 3 \mathrm{~s} / \mathrm{p}={ }^{\prime} 1^{\mathrm{a}}, \mathrm{2}^{\mathrm{a}}, 3^{\mathrm{a}}$ pessoa do discurso, no 'singular' e no 'plural'. A marcação da pessoa do discurso pelo movimento na estrutura do sinal é indicada antes e depois do verbo. A marcação do argumento locativo pelo movimento na estrutura do sinal é indicada por letra minúscula no verbo e no respectivo argumento. Alguns dados são apresentados em imagens.

6 No original: "The term 'interlanguage' was coined by the American linguist, Larry Selinker, in recognition to the fact $L 2$ learners construct a linguistic system that draws, in part, on the learner's $\mathrm{L} 1$ but is also different from it and also from the target language. A learner's interlanguage is, therefore, a unique linguistic system.". 
LO são orais-auditivas. Desse contraste resulta a possibilidade de interferência negativa no desenvolvimento linguístico, uma vez que o sistema pronominal da LS, baseado na apontação, distingue-se formalmente do sistema pronominal da LO, como será demonstrado. A questão que se coloca é, portanto, como se desenvolve o conhecimento dos itens lexicais relevantes e de sua distribuição sintática, mediante o acesso ao input linguístico da língua alvo e as restrições impostas pela L1.

Para tanto, examinamos a interlíngua de surdos em contexto educacional, considerando grupos de estudantes distribuídos em diferentes séries do Ensino Fundamental. Considerando que o input da língua alvo é obtido primordialmente no contexto educacional, nossa hipótese é a seguinte: quanto mais avançado no nível acadêmico, mais avançado será o conhecimento do sistema pronominal.

Nossa análise será desenvolvida como a seguir: na seção 2, apresentamos a fundamentação teórica, que inclui uma análise do sistema pronominal na LIBRAS, considerando posteriormente o sistema pronominal do português; na seção 3, apresentamos a metodologia e a análise dos resultados do estudo experimental; na seção 4, apresentamos as considerações finais.

\section{Os pronomes sujeito na LSB e no português}

\section{O sistema pronominal na LSB}

Nesta seção, apresentamos algumas propriedades do sistema pronominal da LSB, considerando particularmente sua ocorrência na posição de sujeito. Em LIBRAS, os pronomes pessoais são realizados pela apontação (IX) do ponto no espaço que correspondeao referente e desempenham funções semelhantes àquelas desempenhadas pelos elementos nominais (substantivos). Nesse sentido, os pronomes podem substituir um sintagma nominal, que tem como núcleo um substantivo na estrutura oracional, conforme exemplificado a seguir:

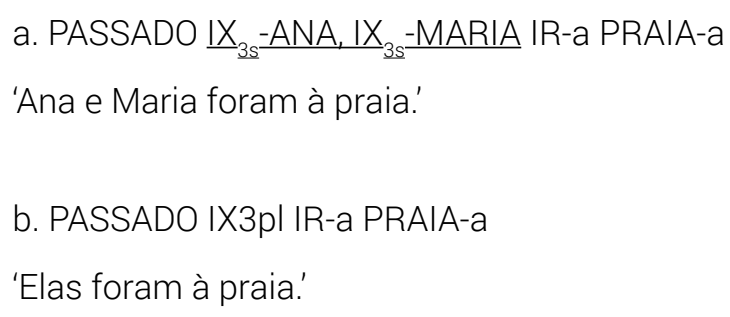

Os exemplos (3a) e (3b) mostram que o sinal <|X3pl> substitui o sintagma nominal formado pelos núcleos nominais 'ANA / MARIA', na posição de sujeito. 
Na LSB, os pronomes pessoais* também ocorrem na posição de objeto, em substituição a um sintagma nominal referido anteriormente, conforme exemplificado a seguir:

(4)

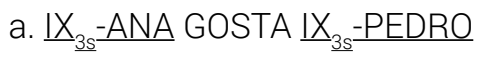

'Maria gosta de Pedro.'

b. $\underline{\underline{I X}} \underline{\underline{3}} \underline{-A N A}$ GOSTA $\underline{\underline{I X}} \underline{\underline{3 S}}$

'Maria gosta dele.'

Os pronomes pessoais da LSB estão sistematizados no Quadro 1 e ilustrados na Figura 1.

Quadro 1. Pronomes pessoais na LSB

\begin{tabular}{|c|c|c|c|}
\hline Pessoa & Número & Transcrição & Descrição \\
\hline $1^{\mathrm{a}}$ & \multirow[t]{3}{*}{ Singular } & EU & aponta para o peito do emissor (a pessoa que fala). \\
\hline $2^{a}$ & & VOCE & aponta para o receptor (a pessoa com quem se fala) \\
\hline $3^{a}$. & & ELE/ ELA & $\begin{array}{l}\text { aponta para um ponto no espaço de sinalização } \\
\text { (a pessoa de quem se fala) }\end{array}$ \\
\hline $1^{\mathrm{a}}$. & \multirow[t]{3}{*}{ Plural } & NÓS & $\begin{array}{l}\text { realiza um movimento circular na frente do peito do } \\
\text { emissor. }\end{array}$ \\
\hline $2^{a}$ & & VOCÊS & $\begin{array}{l}\text { aponta para pessoas e se desloca de forma a abarcar os } \\
\text { referentes. }\end{array}$ \\
\hline $3^{a}$ & & ELES/ELAS & $\begin{array}{l}\text { aponta para duas ou mais pessoas que não estão na } \\
\text { conversa ou para um lugar convencionado. }\end{array}$ \\
\hline
\end{tabular}

Fonte: Adaptado de Andrade (2016, p. 25)

Figura 1. Sistema pronominal em LSB

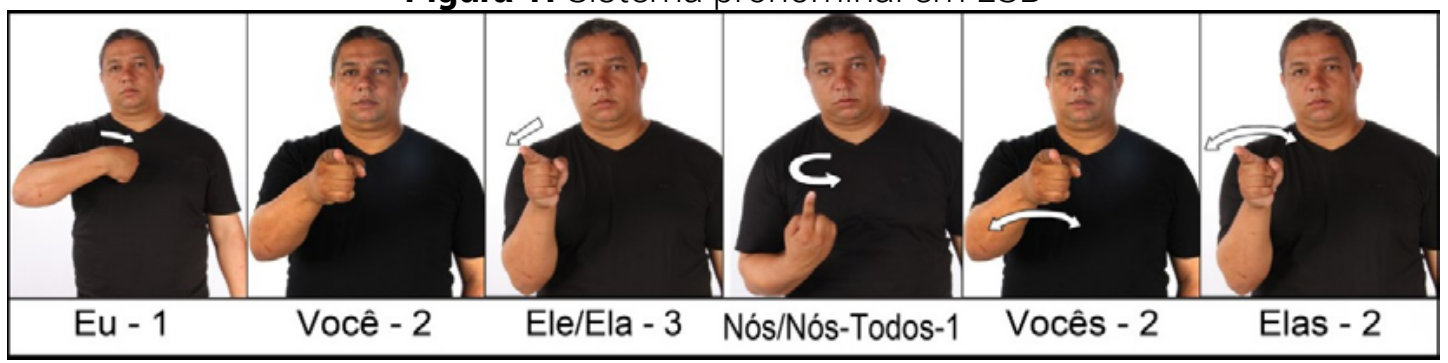

Fonte: Andrade (2016, p. 216) 
O sistema pronominal em LIBRAS é analisado de forma sistemática em Ferreira Brito $(2010[1995])^{7}$. A autora analisou os pronomes pessoais na língua de sinais americana e na LIBRAS, em uma perspectiva comparada, sustentando que:

[...] pronomes em LIBRAS e ASL preenchem a definição de pronomes elaborada por Lyons (1977); a orientação é um parâmetro importante para os sistemas pronominais; a localização em LIBRAS e em ASL representa mais do que apenas uma locação no mundo real. (FERREIRA BRITO, 2010 [1995], p. 85).

Ferreira Brito (2010) ressalta que há três classes de expressões referenciadoras: os nomes próprios, os sintagmas nominais e os pronomes. Como substituto do substantivo, os pronomes teriam como função básica a dêixis, ou seja, a ocorrência dos pronomes indicaria uma localização no espaço e no tempo, dentro do contexto.

Ferreira Brito (2010, p. 47) observa ainda que, na LSB, a flexão de pessoa e número pode ser indicada em verbos direcionais pela mudança na posição inicial e final do movimento. É o caso do verbo 'ENTREGAR', ilustrado a seguir: a orientação diferencia o referente, pois o argumento na posição de sujeito é identificado com o ponto inicial do movimento, e o argumento na posição de objeto é identificado com o ponto final do movimento (ver também Quadros e Karnopp, 2004), conforme exemplificado a seguir.

(5) 1s-ENTREGAR-2s

'Eu entrego para você'

(6) 2s-ENTREGAR-1s

'Você entrega para mim'

(7) 3s-ENTREGAR-3s

'Ele/a entrega para ele/ela'

7 Na primeira referência à obra Por uma gramática da língua de sinais, destacamos a data da $1^{\text {a }}$ edição entre colchetes, após a data da edição consultada, para situar cronologicamente a contribuição da autora. Nas citações seguintes, indicamos apenas a data da edição consultada (2010). 
Figura 2. Ilustração de (5), (6) e (7)

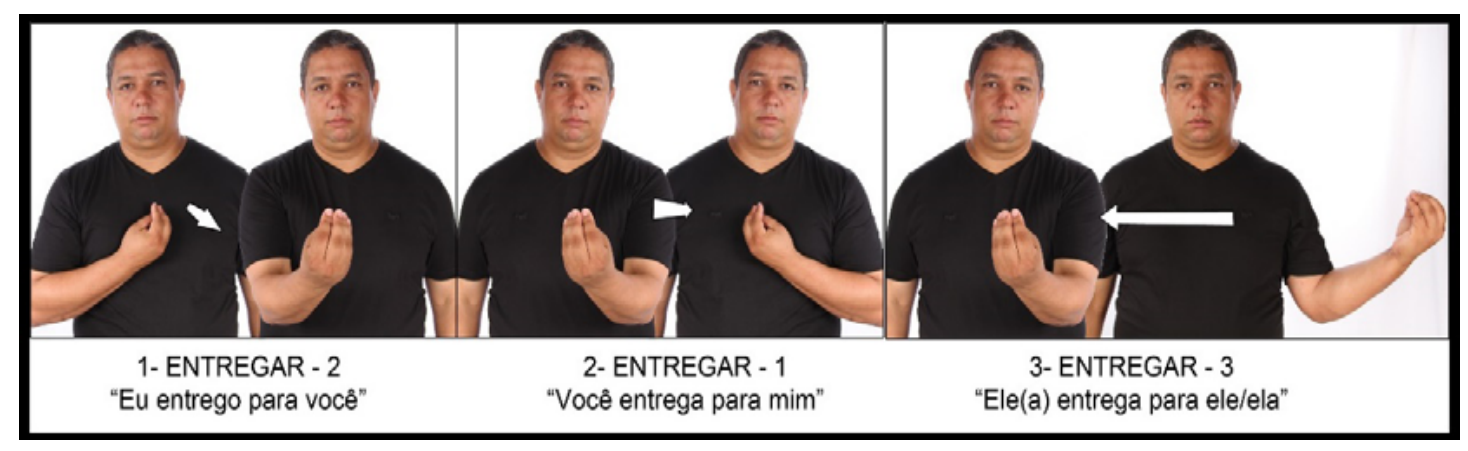

Fonte: Arquivo próprio

Em estudo prévio, Andrade (2016) observa que a flexão de $1^{a}, 2^{a}$ e $3^{a}$ pessoa está incorporada no verbo de concordância, no singular. No entanto, no plural, é necessário recorrer à apontação, por meio dos sinais que indicam 'dual', 'trial', 'múltiplo', também com verbos de concordância, como no exemplo a seguir. $\mathrm{Na} 1^{\mathrm{a}}, 2^{\mathrm{a}}$ e $3^{\mathrm{a}}$ pessoa do plural é necessário utilizar a sinalização/apontação, ou seja, o sinal independente, conforme sistematizado no Quadro 1 e ilustrado na Figura 1.

Outro aspecto relevante em relação à sintaxe dos pronomes em LSB é que, na $1^{\text {a }}$ pessoa do singular, a apontação orientada para o corpo do sinalizador não é usada. Nesse caso, a ausência da apontação indica a $1^{\text {a }}$ pessoa, em oposição ao uso da apontação para a $2^{a}$ e a $3^{a}$ pessoa, como ilustrado a seguir, com o verbo GOSTAR:

(8) 1s-GOSTAR CHOCOLATE. 'Eu gosto de chocolate.'

(9) IX ${ }_{2 S}$ GOSTAR CHOCOLATE. 'Você gosta de chocolate.'

(10) IX $\mathrm{X}_{3 \mathrm{~s}}$ GOSTAR CHOCOLATE. 'Ele gosta de chocolate.'

A figura a seguir ilustra os dados em (8), (9), (10): 
Figura 3. Ilustração dos dados em (8), (9) e (10)

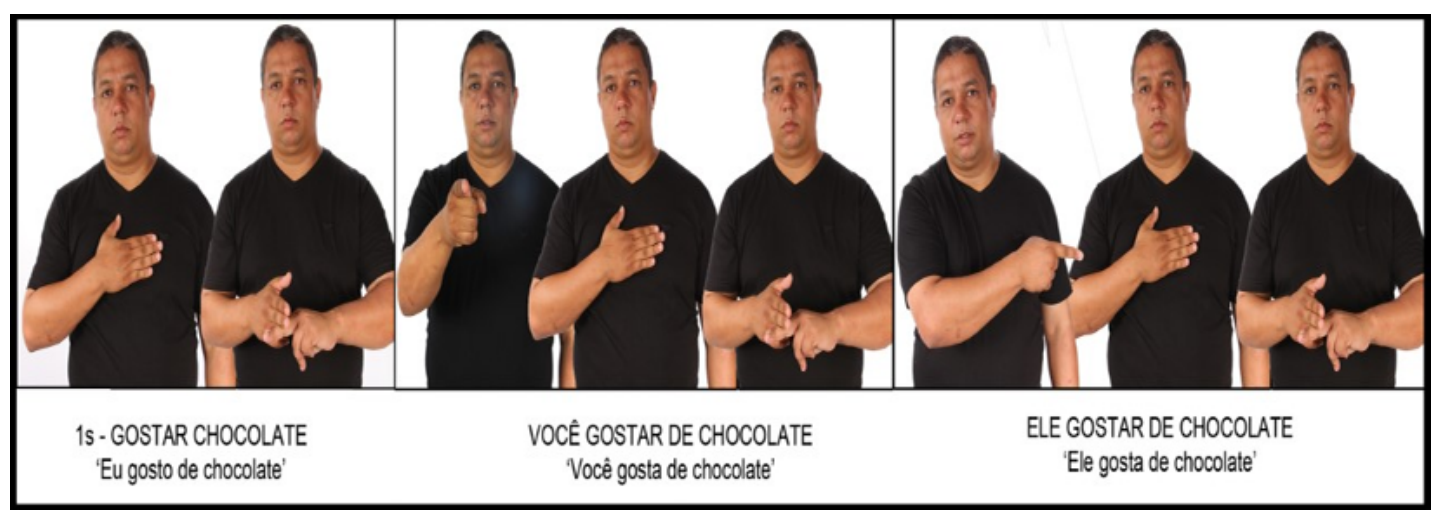

Fonte: Arquivo próprio

Ferreira Brito (2010 [1995], p. 48) conclui que a LSB é uma língua "pro-drop", ou seja, possui o sujeito nulo. Além disso, o objeto também pode ser nulo, como no caso do verbo de concordância, ilustrado de (5) a (7). Nesse sentido, no discurso, o sujeito e o objeto podem ser nulos no enunciado. Em relação aos verbos com concordância, verificamos que o uso da apontação na LSB é necessário quando o referente está no plural, por meio dos sinais "DUAL", "TRIAL" ou "VÁRIOS". Nesse sentido, podemos afirmar que a apontação ocorre com verbos sem concordância e com verbos com concordância.

Verificamos também que, na $1^{a}$ pessoa do singular, a apontação não é realizada se o ponto de articulação do sinal é o corpo do sinalizador. Esse fato é considerado em detalhe no estudo de Meir et al. (2006), que analisa a hipótese de que o ponto de articulação seja um fator a determinar a tipologia verbal, referida como "corpo como sujeito". Essa hipótese será considerada na análise dos dados experimentais.

Ferreira Brito (2010 [1995], p. 92) acrescenta que o sistema pronominal na LSB é realizado pela apontação, pela orientação do movimento e pela orientação do olhar, conforme descrito a seguir.

1) a localização com um componente interno da estrutura de um sinal;

2) a localização com parte do espaço de enunciação usada como a estrutura para os pronomes (a interpretação espacial linguística dos referentes);

3) a localização real dos participantes conversacionais e dos referentes de terceira.

A autora afırma que os primeiros níveis citados são linguísticos e convencionais, diferentes do terceiro nível. Em relação à $1^{a}$ pessoa, os níveis são considerados em um mesmo espaço físico, ou seja, em frente ao corpo do emissor, na altura do tórax, já que o espaço 
de enunciação é ligado sempre ao corpo do emissor. Essa ocorrência de três níveis de localização no corpo do emissor em $1^{\text {a }}$ pessoa causa uma sobreposição de níveis. No que se refere à $2^{a}$ pessoa, a realização dos três níveis não coincide. No caso da $3^{a}$ pessoa, a referência é bem mais complexa, pois os três níveis de localização são todos diferentes.

A seguir, explicaremos mais detalhadamente cada um dos níveis citados, conforme Ferreira Brito (2010). Em LIBRAS, o parâmetro da localização (LOC) para as três pessoas é a área em frente ao tórax. No caso dos pronomes pessoais, acontecem certas variações alofônicas, ou seja, a localização pode variar dentro de uma determinada faixa, por exemplo, "o parâmetro de localização do pronome de primeira pessoa pode ser o espaço neutro como o centro do tórax propriamente dito" (FERREIRA BRITO, 2010, p. 93). A autora ressalta que a expressão linguística da referência de pessoa, do ponto de vista viso-espacial, pode se transformar em gestualização paralinguística, como um recurso comunicativo ${ }^{8}$.

A orientação do olhar pode ser dirigida na direção da segunda pessoa ou da terceira pessoa. Focando na segunda pessoa, o emissor indica com o olhar o interlocutor. $\mathrm{Na}$ terceira pessoa, o emissor dirige o olhar para o interlocutor para enfocar a localização do referente, no espaço físico. Na orientação de mão, o dedo indicador aponta para o próprio corpo do enunciador, o que significa a primeira pessoa do singular "eu". Na $2^{a}$ pessoa e na $3^{a}$ pessoa, o dedo indicador aponta na direção do referente, mas esse movimento é acompanhado pela orientação do olhar. A diferença é que, na $2^{a}$ pessoa, o enunciador faz a orientação do olhar na direção do interlocutor, e na terceira pessoa a orientação muda para uma localização no espaço de sinalização. Ou seja, o enunciador orienta a apontação e o olhar na direção do ponto onde está o referente. Esse referente pode estar presente ou não. Dependendo da pessoa do discurso, a direção do olhar deve se ligar com a estrutura da interação.

Quadros (1997) afirma que os pronomes pessoais de $3^{\mathrm{a}}$ pessoa apontam para o referente no contexto do discurso, que pode estar presente ou ausente. Caso o discurso tenha um referente presente ou ausente, a referência de apontação pode se apresentar direcionada a um local marcado por quem fala. Lillo-Martin e Klima (1990 apud QUADROS, 1997, p. 193) ressaltam que, quando há uma situação de sinalização de terceira pessoa nãopresente, o indivíduo pode indicar um ponto convencional à direita ou à esquerda. Por exemplo, o sinalizador introduz os participantes, "João" e "Maria" com uso de alfabeto manual, logo não vai repetir a referência da terceira pessoa, então aponta na direção do local definido para "Maria" pelo lado esquerdo e "João", pelo lado direito. Passamos a analisar brevemente o sistema pronominal do português.

8 A apontação pronominal e a indicação verbal como estratégias orientadas para suprir demandas comunicativas podem ser analisadas em termos da teoria dos espaços mentais e da linguística cognitiva (cf. MOREIRA, 2007). A discussão sobre tais estratégias foge ao escopo deste trabalho. 


\section{0 sistema pronominal no português brasileiro}

Estudos gramaticais do português brasileiro no âmbito da linguística apontam um sistema inovador em relação ao português europeu (e à descrição das gramáticas tradicionais). Em particular, os pronomes pessoais indicam, no discurso: (a) Quem fala: $1^{a}$ pessoa; (b) Com quem se fala; (c) De quem se fala: $3^{a}$ pessoa. Têm também a capacidade de retomar uma forma nominal expressa anteriormente, conforme ilustrado em (11), em que o pronome "ela" retoma o sintagma nominal "a menina":

A menina estava inquieta, ela queria sair dali.

Os pronomes pessoais no português apresentam formas distintas, dependendo da função que exercem na oração (CUNHA, 1980). Quanto à função, eles podem ser retos ou oblíquos. São retos quando funcionam como sujeito da oração. São oblíquos quando funcionam como complemento verbal ou como complemento de preposição, conforme indicado no Quadro 2. Não vamos nos deter na análise dos pronomes oblíquos, uma vez que o presente estudo está voltado para os pronomes na posição de sujeito.

Quadro 2. Pronomes pessoais no português brasileiro (escrito)

\begin{tabular}{|c|c|c|c|c|c|c|}
\hline & & \multirow[t]{2}{*}{$\begin{array}{l}\text { Pronomes } \\
\text { pessoais } \\
\text { retos }\end{array}$} & \multicolumn{2}{|c|}{$\begin{array}{l}\text { Pronomes pessoais do caso } \\
\text { oblíquo } \\
\text { (não reflexivos) }\end{array}$} & \multicolumn{2}{|c|}{$\begin{array}{l}\text { Pronomes pessoais dc } \\
\text { caso oblíquo (reflexivos) }\end{array}$} \\
\hline & & & Átonos & Tônicos & Átonos & Tônicos \\
\hline $\begin{array}{l}1^{a} \text { pessoa } \\
2^{a} \text { pessoa } \\
3^{a} \text { pessoa }\end{array}$ & Singular & $\begin{array}{l}\text { Eu } \\
\text { Você } \\
\text { Ele, ela }\end{array}$ & $\begin{array}{l}\text { Me } \\
\text { Te } \\
\text { O, a, the }\end{array}$ & $\begin{array}{l}\text { (para) mim, } \\
\text { (para) ti } \\
\text { (para) ele/ ela }\end{array}$ & $\begin{array}{l}\text { Me } \\
\text { Te } \\
\text { Se }\end{array}$ & $\begin{array}{l}\text { Mim } \\
\text { Ti } \\
\text { Si; ele/a }\end{array}$ \\
\hline $\begin{array}{l}1^{a} \text { pessoa } \\
2^{a} \text { pessoa } \\
3^{a} \text { pessoa }\end{array}$ & Plural & $\begin{array}{l}\text { Nós } \\
\text { vocês } \\
\text { Eles, elas }\end{array}$ & $\begin{array}{l}\text { Nos } \\
--- \\
\text { Os, as, Ihes }\end{array}$ & $\begin{array}{l}\text { (para) nós; } \\
\text { (para) vocês } \\
\text { (para) eles/ } \\
\text { elas }\end{array}$ & $\begin{array}{l}\text { Nos } \\
\text { Se } \\
\text { Se }\end{array}$ & $\begin{array}{l}\text { Nós; } \\
\text { Vocês } \\
\text { Si, Eles/elas }\end{array}$ \\
\hline
\end{tabular}

Fonte: Elaboração própria

Adotando uma perspectiva comparada entre a LSB e o português, Ferreira Brito (2010) faz a distinção entre a dêixis pura e impura. Enquanto, em português, os pronomes eu e você são considerados como dêixis puras, porque são apenas dêicticos, os pronomes ele e ela são considerados dêixis impuras porque veiculam informação adicional, como gênero, marcadores sociais e de polidez, que podem ser de natureza expressiva ou descritiva. A autora acrescenta que, em LIBRAS, a $1^{a}$, a $2^{a}$ e a $3^{a}$ pessoa do singular são dêixis puras. 
O contraste entre o português e a LSB tem relevância para a análise da interferência da L1 na gramática da interlíngua, pois mostra que o português brasileiro, mas não a LSB, manifesta uma cisão no sistema pronominal de caráter descritivo, uma vez que os pronomes de $3^{a}$ pessoa são marcados para o gênero gramatical, o que configura a dêixis impura. Além disso, a marcação dos referentes por meio do movimento na estrutura do sinal na LSB nos chamados verbos direcionais/de concordância constitui um contraste relevante em relação à língua oral. Na seção a seguir, esse contraste será retomado, mediante uma análise em que será estabelecida uma relação com o traço de animacidade, a ser considerado na análise da interferência da L1 no desenvolvimento linguístico.

\section{Uma proposta de revisão para a classificação dos verbos nas Línguas de Sinais}

Um aspecto significativo da gramática das línguas de sinais é a distinção entre verbos simples e verbos direcionais. Conforme mencionado anteriormente, verbos direcionais manifestam informação morfossintática em relação à função de sujeito, objeto direto, adjunto locativo na estrutura oracional (cf. FERREIRA BRITO, 2010). Essa distinção é retomada por Quadros e Karnopp (2004), que, seguindo análise de Klima e Bellugi (1979) para a Língua de Sinais Americana (American Sign Language), propõem uma classificação para os verbos na LSB em função da presença de afixos flexionais (de pessoa e número) e de afixos locativos. Enquanto verbos simples, como AMAR e GOSTAR (cf. exemplos (2) e (4)) não apresentam tais afıxos, verbos de concordância, como ENTREGAR (cf. exemplos (5)-(7)), manifestam traços flexionais de pessoa e número, uma vez que o início e fim do movimento e a direção estabelecem as formas verbais para pessoa incorporando pontos previamente indicados no espaço para determinados referentes. Verbos espaciais, como IR (cf. exemplo (3)), apresentam afixos locativos, pois o movimento incorpora o ponto que determina a referência do argumento locativo.

Essa proposta de classificação é revisada posteriormente no sentido de incluir um aspecto relevante na realização dos argumentos do predicado, que é o uso do corpo do sinalizador. De acordo com Meir et al. (2008, p. 87), "a função básica do corpo nas formas verbais em uma língua de sinais é representar o argumento sujeito". O corpo do sinalizador não é só um lugar para articulação do sinal, mas pode expressar um significado particular ou uma função específica. Os autores argumentam que, em verbos ancorados no corpo (icônicos), o corpo representa o sujeito. Em relação ao verbo COMER, por exemplo, na Língua de Sinais Americana (ASL) e na Língua de Sinais Israelense (ISL), a mão apresenta uma configuração particular " "movendo-se em direção à boca a partir de uma localização à sua frente e repete este movimento por duas vezes" (p. 88). Nesse sentido, a Estrutura Conceitual Lexical poderia ser representada como a seguir:

$$
\mathrm{X} \text { causa [Y ir [para dentro da boca de } \mathrm{X}]]
$$


Na realização do sinal, o corpo é um componente formacional e representa $X$, o agente. É importante observar que o sinal COMER é realizado na boca do sinalizador, mas o agente $X$ pode ter como referente a $1^{a}$, a $2^{a}$ ou a $3^{a}$ pessoa, e a realização do sinal não muda. Nos sinais em que o corpo é um componente formacional, o argumento relacionado ao corpo pode ser associado a diferentes papeis temáticos: agente, paciente, experienciador e receptor. Se o predicado é de um só lugar, o corpo é associado a esse argumento. Se o predicado é um verbo transitivo, o argumento que se identifica com o corpo é: (i) o agente, em verbos de dois argumentos <agente, paciente>, como COMER, BEBER, OLHAR, e de três argumentos <agente, paciente, receptor>, como PERGUNTAR, INFORMAR, EXPLICAR, e (ii) o experienciador e preceptor, em verbos de dois argumentos < experienciador/perceptor, tema>, como VER, OUVIR, AMAR.

Seguindo os princípios do mapeamento entre as estruturas temática e sintática de autores como Fillmore (1968), Jackendoff (1990), Falk (2006) e outros, citados pelos autores, a generalização é que o corpo corresponde ao argumento-sujeito do verbo e não a um papel temático específico. A conclusão é que, nesses verbos, "o padrão básico de lexicalização é o CORPO COMO SUJEITO” (p. 90). Uma consequência dessa análise é que, na $1^{a}$ pessoa, o sujeito é marcado no corpo do sinalizador, enquanto na $2^{a}$ e na $3^{a}$ pessoa, o sujeito será marcado por meio da apontação. Cabe, ainda, destacar que nem todos os verbos usam o corpo como componente formacional. Além disso, o corpo representa o sujeito apenas para seres animados. Essa restrição indica que o uso do corpo, em oposição à apontação, distingue o traço [+/-animado] em função do tipo de verbo.

Os autores acrescentam que os verbos de concordância se distinguem do padrão "o corpo como sujeito" porque incorporam a categoria gramatical de pessoa. Essa análise já havia sido formulada em estudos prévios das LSB (cf. FERREIRA BRITO, 2010 [1995]), QUADROS; KARNOPP, 2004). No contraste com os verbos que recorrem ao padrão "corpo como sujeito", Meir et al. (2008, p. 93) observam que, nos verbos de concordância, a pessoa gramatical é codificada "por meio do emprego do contraste entre o sinalizador e o espaço em sua volta", ou seja, os verbos de concordância adotam a oposição corpo-espaço para codificar a categoria gramatical pessoa ( $7^{\text {a }}$ pessoa versus não- $7^{\text {a }}$ pessoa), enquanto o movimento e a orientação das mãos codificam os papéis sintáticos dos argumentos (SUJEITO-OBJETO). Considerando-se que essa classe de verbos denota uma relação de transferência, os argumentos tendem a ser marcados para o traço [+animado], tanto na posição de sujeito, quanto na posição de objeto.

Adotamos a proposta de Meir et al. (2008) na análise dos verbos na LSB e do efeito da interferência na L1 na interlíngua, tendo em vista a relação entre a tipologia proposta e o traço de animacidade dos argumentos selecionados. 


\section{0 estudo da interlíngua}

\section{Metodologia e coleta dos dados}

Neste estudo, apresentamos os resultados de um dos testes realizados no âmbito do estudo de Andrade (2016), organizados em novo formato e discutidos em nova perspectiva teórica ${ }^{9}$. Conforme mencionado, o objetivo do estudo é o de investigar o desenvolvimento do sistema pronominal na interlíngua do surdo (falante de LSB como L1) aprendiz do português (escrito) como L2, mediante a hipótese da interferência da L1 pelo acesso (parcial) à GU. Adotando a metodologia experimental na constituição do corpus, definimos como variável dependente o uso (convergente) do pronome pessoal na posição de sujeito em sentenças que retomam um antecedente.

Os dados foram produzidos por estudantes do $9^{\circ}$ ano do Ensino Fundamental e do $1^{\circ} \mathrm{e}$ do $2^{\circ}$ ano do Ensino Médio de duas escolas estaduais inclusivas da cidade de São João del Rei, Minas Gerais: Escola Estadual Inácio Passos e Escola Estadual Doutor Garcia de $\operatorname{Lima}^{10}$. O evento de coleta dos dados ocorreu no $2^{\circ}$ semestre de 2015. Os participantes eram surdos profundos, proficientes na Língua de Sinais Brasileira.

Os participantes foram distribuídos nos seguintes grupos:

Grupo I: três alunos do $9^{\circ}$ ano do Ensino Fundamental;

Grupo II: quatro alunos do $2^{\circ}$ ano do Ensino Médio;

Grupo III: cinco alunos do $3^{\circ}$ ano do Ensino Médio.

Na análise, adotamos a perspectiva transversal, mediante a hipótese de que o input linguístico da aquisição aumenta em função do nível acadêmico dos participantes. Neste trabalho, apresentamos os resultados da atividade 1, que consistia de 10 (dez) enunciados, em que os alunos deveriam preencher a lacuna com o pronome, estabelecendo uma

\footnotetext{
9 O estudo de Andrade (2016) investigou a interlíngua de surdos em contexto educacional, por meio de dois tipos de teste: o teste 1, semiestruturado (reportado neste estudo) de preenchimento de lacuna, e o teste 2 , de produção textual espontânea (com apoio de imagem motivadora). A decisão de apresentar o teste 1 (e não o 2) se justifica, primordialmente, em função do interesse em discutir o papel do traço de animacidade no antecedente, que se depreende no referido teste.

10 A direção da escola, os participantes, assim como os pais/responsáveis emitiram carta de livre consentimento para a realização da pesquisa.
} 
relação anafórica com um sintagma nominal destacado na oração anterior, conforme ilustrado a seguir ${ }^{11}$.

Complete as orações, substituindo as palavras destacadas por pronomes pessoais.

a) Layse e Fabiana são amigas. se dão bem.

b) Quebrei um prato. era de cristal.

Tabela 1. Número de acertos no uso do pronome vs. nível acadêmico dos participantes

\begin{tabular}{c|c|c|c|c}
\hline Enunciado & Relação anafórica & $\begin{array}{c}\text { Grupo I } \\
\mathbf{9}^{\circ} \text { ano [3] }\end{array}$ & $\begin{array}{c}\text { Grupo II } \\
\mathbf{2}^{\mathbf{0}} \text { ano [4] }\end{array}$ & $\begin{array}{c}\text { Grupo III } \\
\mathbf{3}^{\circ} \text { ano [5] }\end{array}$ \\
\hline 1 & {$[$ Layse e Fabiana]/Elas } & 2 & 4 & 5 \\
\hline 2 & {$[$ Eu e Luana]/Nós } & 0 & 0 & 0 \\
\hline 3 & {$[$ André]/Ele } & 3 & 1 & 5 \\
\hline 4 & {$[$ O prato]/Ele } & 0 & 0 & 3 \\
\hline 5 & {$[$ As flores]/Elas } & 0 & 1 & 2 \\
\hline 6 & {$[$ Os pássaros]/Eles } & 0 & 1 & 2 \\
\hline 7 & {$[$ Anna]/Ela } & 2 & 3 & 5 \\
\hline 8 & {$[$ Antônio e eu]/Nós } & 1 & 1 & 0 \\
\hline 9 & {$[$ Você e eu]/Nós } & 0 & 1 & 0 \\
\hline 10 & {$[$ A professora]/Ela } & 2 & 3 & 5 \\
\hline TOTAL & & $10 / 30$ & $15 / 40$ & $27 / 50$ \\
& & $(33,3 \%)$ & $(37,5 \%)$ & $(54 \%)$ \\
\hline
\end{tabular}

Fonte: Elaboração própria

Em relação ao total de acertos, verificamos aumento no percentual de usos convergentes (acertos) dos pronomes pessoais na posição de sujeito, em função do nível de escolarização $(33,3 \%>37,5 \%>54 \%)$. Procedemos à análise da proporção de acertos (SIM), em oposição aos erros (NÃO), considerando a hipótese de que é igual a 0,5 (50\%) (hipótese nula). Verificamos que, nos resultados dos grupos I e III, que correspondem aos pontos inicial e final dos níveis acadêmicos examinados, a proporção de acertos (SIM) tem significância estatística ( $p$-valor= 0,0052). Também entre os grupos I-II, a proporção de acertos (SIM) tem significância estatística ( $p$-valor=0,02). Não foi observada significância

11 Com o objetivo apenas de criar uma motivação visual, cada frase vinha acompanhada de uma pequena ilustração, que remetia a algum aspecto da situação descrita no enunciado. 
estatística na proporção de acertos entre os grupos II e III (p-valor=0,59). Concluímos que a dependência entre os resultados dos níveis [I-III] e [I-II] permite afırmar que existe relação entre o aumento no número de acertos no uso do pronome e o nível acadêmico dos participantes.

Considerando os tipos de estruturas envolvidas, verificamos que os participantes do terceiro grupo ( $3^{\circ}$ ano) alcançam $100 \%$ de acertos nos contextos em que os pronomes têm como antecedente os sintagmas nominais "Layse e Fabiana", "André", "Ana" e "A professora".

Diferentemente, em 3 (três) contextos, verifica-se total ausência de acertos no nível do $3^{\circ}$ ano (embora haja três acertos nos níveis anteriores). Nesse caso, os antecedentes dos pronomes são constituídos por um sintagma nominal pleno coordenado com um sintagma pronominal na $1^{\text {a }}$ pessoa "eu", que exigiria a retomada anafórica pelo pronome "nós" (a única maneira de testar o uso desse pronome sem repeti-lo na sentença anterior). São eles "Eu e Luana", "Antônio e eu", "Você e eu".

Nas três demais sentenças, que têm como antecedente os sintagmas nominais "o prato", "as flores", "os pássaros", verifica-se aumento no uso convergente do pronome pessoal em função dos níveis de escolarização, embora o resultado no terceiro grupo ( $2^{\circ}$ ano) não alcance pleno acerto.

Passamos à discussão dos resultados obtidos, buscando identificar fatores que favorecem a distribuição dos acertos, tendo em vista a hipótese da interferência da L1. Essas questões serão analisadas em perspectiva quantitativa e qualitativa.

\section{Discussão}

Os resultados da atividade 1 permitem observar que existe desenvolvimento linguístico em relação à proporção de acertos entre os grupos I e III e I e II, tendo em vista a significância estatística dos resultados. Cabe ainda notar que o resultado do presente estudo alinhase com estudos prévios, que examinam a interlíngua dos surdos por meio de uma abordagem transversal, considerando o nível acadêmico dos participantes. É o caso, por exemplo, do estudo de Chan-Vianna (2003), que examina o desenvolvimento linguístico em relação ao uso de sintagmas nominais possessivos, abordando ainda o papel da L1, pela análise do efeito da interferência (positiva e negativa) da LSB em relação aos fenômenos citados. A autora demonstra a tendência de aumento no uso da preposição introdutora do sintagma possuidor, com o aumento da escolarização, bem como o efeito da interferência (negativa) da L1 nas séries iniciais, pela presença de estruturas na ordem possuidor-possuído, consistente com o uso de estruturas topicalizadas observadas na Língua de Sinais Brasileira (L1) e divergente em relação à língua alvo. 
A análise dos dados em relação aos tipos de pronomes permite afırmar que o desenvolvimento linguístico se manifesta de forma consistente com pronomes de $3^{a}$ pessoa. O pronome de $1^{a}$ pessoa do plural (nós), anafórico de um sintagma nominal composto com a $1^{\text {a }}$ pessoa do singular (Eu e Luana/Antônio e eu/Você e eu) colocam dificuldade para todos os grupos, embora tenha sido observado um único acerto nos grupos I e II, perfazendo um total de 3 acertos em um total de 36 respostas a essas sentenças, ou 0,83\% desse total, o que constitui um resultado inconclusivo. A ausência de acerto no Grupo III sugere que essa estrutura não está suficientemente robusta no input da aquisição. Nesse sentido, não existe desenvolvimento linguístico para o uso desse pronome da língua alvo (português L2) nesse tipo de estrutura.

Considerando-se as sentenças em que se verificam os usos do pronome de $3^{a}$ pessoa, constatamosqueo pronomede $3^{a}$ pessoa anafórico do sintagmanominal dotipo[-humano]/ [-animado] ("o prato"/"as flores"/"os pássaros") colocou dificuldade para os três grupos. Essa dificuldade é observada nos grupos I e II. O grupo III demonstra desenvolvimento linguístico em relação à língua alvo, uma vez que identificamos crescimento na taxa de acerto. Inversamente, podemos afirmar que os sintagmas nominais do tipo [+humano]/ [+animado] tendem a favorecem o uso adequado do pronome de $3^{\mathrm{a}}$ pessoa.

A análise qualitativa dos resultados permite concluir que os estudantes têm conhecimento dos itens lexicais 'eu', 'nós', 'você', 'ele(s)/ela(s)', mas ainda demonstram dificuldade na definição da referência de pessoa e na flexão de gênero e número.

Considerando a hipótese do acesso (parcial) à GU e da interferência da L1 - no caso, a LSB -, verificamos que o traço de animacidade pode ser um fator relevante no desenvolvimento do sistema pronominal da língua alvo. Conforme mencionado anteriormente, na análise do sistema pronominal na L1, o traço de animacidade está marcado no sistema pronominal da LSB, uma vez que, no padrão "o corpo como sujeito" (verbos simples), o argumento sujeito é sempre animado; enquanto no padrão "oposição corpo-espaço" (verbos de concordância), em que o corpo marca a $1^{\text {a }}$ pessoa e o espaço marca a não- ${ }^{\text {a }}$ pessoa, o uso do movimento descreve uma transferência entre dois argumentos, ambos marcados para o traço [+animado] ${ }^{12}$. No sistema pronominal do português, a animacidade é marcada uniformemente na oposição $1^{\mathrm{a}} / 2^{\mathrm{a}}$ pessoa versus $3^{\mathrm{a}}$ pessoa: enquanto os pronomes de $1^{\mathrm{a}}$ e a $2^{\mathrm{a}}$ pessoa são inerentemente marcados para o traço [+animado], os pronomes de $3^{a}$ pessoa não o são. Concluímos preliminarmente que esse contraste pode ser o fator que explica o desenvolvimento linguístico com pronomes de $3^{a}$ pessoa com antecedente marcado para o traço [+animado], confirmando-se a

12 A marcação consistente para o traço [+animado] nesses grupos de verbos não exclui a existência de verbos que selecionam argumento marcado para o traço [-humano] e [-animado]. 0 estudo de Meir et al. (2008), referido anteriormente, indica que esse tipo de sujeito pode ser expresso por verbos realizados por classificadores. Trata-se de uma questão que requer aprofundamento em estudo futuro. 
interferência positiva da L1. Inversamente, a dificuldade colocada para o uso do pronome de $3^{a}$ pessoa com antecedente marcado para o traço [-animado], confirma a interferência negativa da L1.

\section{Considerações finais}

O estudo investigou o uso do sistema pronominal em dados da interlíngua de surdos (falantes da Língua de Sinais Brasileira) aprendizes de português (escrito) como segunda língua, distribuídos em função do nível de escolarização. Partindo da análise do sistema pronominal da LSB e do português, tendo em vista a hipótese do acesso (parcial) à Gramática Universal na aquisição de português (L2) escrito por surdos e da interferência da L1, conforme White (2003), verificamos que a significância estatística na proporção de acertos no uso dos pronomes pelos participantes distribuídos por níveis acadêmicos aponta para a existência de desenvolvimento linguístico. Os dados da interlíngua apresentam as seguintes características:

(a) Tendência ao uso adequado do pronome de $3^{a}$ pessoa, como anafórico de antecedentes marcados para o traço [+humano] ou [+animado];

(b) Inversamente, o uso inadequado do pronome na $3^{a}$ pessoa, como anafórico de antecedentes do tipo [-animado];

(c) Dificuldade no uso dos pronomes de $1^{\text {a }}$ pessoa do plural como anafórico de um sintagma nominal composto, com a presença do pronome "eu" e outro termo.

Adotando análise translinguística, concluímos preliminarmente que as inadequações no uso do sistema pronominal na interlíngua dos surdos aprendizes de português L2 confirmam a hipótese da interferência da L1. Considerando-se a relevância do traço [+animado] no sistema de marcação de pessoa na LSB (no qual se distinguem verbos do tipo "o corpo como sujeito", em que o referente associado ao papel sintático de sujeito é marcado para o traço [+animado], e verbos que adotam a oposição corpo-espaço, em que o corpo marca "1a pessoa" e o espaço marca "não $1^{a}$ pessoa", e o movimento identifica referentes marcados para o traço [+animado]), é possível explicar a interferência da L1. Os resultados relativos ao desenvolvimento da gramática da língua alvo - português (L2) escrito - apontam para uma tendência de favorecimento do uso convergente dos pronomes de $3^{a}$ pessoa com antecedentes/referentes marcados para o traço [+animado], em oposição aos casos em que os antecedentes são marcados para o traço [-animado].

O presente artigo reportou uma parte do estudo realizado por Andrade (2016), propondo uma análise mais elaborada em relação ao papel do traço de animacidade, tendo em 
vista a tipologia verbal de Meir et al. (2006). Novos dados devem ser coletados a fim de verificar as conclusões preliminares. Esperamos avançar nesse sentido, em estudos futuros.

\section{REFERÊNCIAS}

ANDRADE, T. R. Pronomes pessoais na interlíngua do surdo/a aprendiz de português L2 (escrito). 2016. Dissertação (Mestrado em Linguística) - Instituto de Letras, Universidade de Brasília, Brasília, 2016.

CHAN-VIANNA, A. Aquisição de português por surdos: estruturas de posse. 2003. Dissertação (Doutorado em Linguística) - Instituto de Letras, Universidade de Brasília, Brasília, 2003.

CHOMSKY, N. O Conhecimento da Língua - sua natureza, origem e uso. Tradução Anabela Gonçalves e Ana Teresa Alves. Lisboa: Caminho, 1994.

CHOMSKY, N. O Programa Minimalista. Tradução Eduardo P. Raposo. Lisboa: Caminho, 1999.

CUNHA, C.; CINTRA, L. Nova gramática do português contemporâneo. Rio de Janeiro: Nova Fronteira, 1980.

ELIS, R. Second language Acquisition. Oxford: Oxford University Press, 1997.

FELIPE, T. A. LIBRAS em contexto: livro do estudante. MEC/SEESP. (Programa Nacional de Apoio à Educação de Surdos). Brasília, 2007.

FERREIRA, H. A reflexividade/reciprocidade na Língua de Sinais Brasileira. Anais do II Congresso Internacional Línguas, Culturas e Literaturas em Diálogo. Universidade de Brasília, 2018, p. 2077-2088. Disponível em: https://www.Icldialogobrasilia2018.com. Acesso em: 31 ago. 2019.

FERREIRA BRITO, L. Por uma gramática de línguas de sinais. Rio de Janeiro: Tempo Brasileiro UFRJ, 2010.

KLIMA, E.; BELLUGI, U. The signs of language. Cambridge, MA: Harvard University, 1979. 
MEIR, I. et al. Repensando classes verbais em línguas de sinais: o corpo como sujeito. In: QUADROS, M. R.; VASCONCELLOS, B. L. M. Questões teóricas das pesquisas em línguas de sinais. Florianópolis: Editora Arara Azul, 2006. p. 87-106.

MOREIRA, R. L. Uma descrição da dêixis de pessoa na Língua de Sinais Brasileira: pronomes pessoais e verbos indicadores. 2007. Dissertação (Mestrado em Semiótica e Linguística Geral) - Faculdade de Filosofia, Letras e Ciências Humanas, Universidade de São Paulo, São Paulo, 2007.

QUADROS, R. M. Educação de Surdos: a Aquisição da Linguagem. Porto Alegre: Ed. Artes Médicas, 1997.

QUADROS, R.; KARNOPP, L. Língua de sinais brasileira: estudos linguísticos. Porto Alegre: Artes Médicas, 2004.

SELINKER, L. Interlanguage. IRAL, v. 10, n. 3, p. 209-231, 1972.

WHITE, L. Second Language Acquisition and Universal Grammar. Cambridge: Cambridge University Press, 2003. 